\title{
Pengaruh Aspek Sosio Budaya Gizi Terhadap Pemberian Asi Eksklusif Pada Etnik Madura Di Wilayah Kerja Puskesmas Bangkalan, Madura
}

\section{The Effect Of Socio-Culture Of Nutrition On Exclusive Breastfeeding Of Maduranese In Bangkalan Public Health Center, Madura}

\author{
Anis Zaiti Mubarokah*1, Lailatul Muniroh²
}

\begin{abstract}
ABSTRAK
Latar Belakang: ASI merupakan nutrisi terbaik bagi kesehatan dan kecerdasan anak. Pemberian ASI eksklusif dapat mencegah kematian dan penyakit infeksi pada bayi. Faktor sosio budaya merupakan salah satu faktor pendorong yang cukup kuat terhadap perilaku ibu dalam memberikan ASI eksklusif, terutama pada masyarakat yang memiliki kepatuhan yang kuat pada tradisi nenek moyang seperti pada etnik Madura.

Tujuan: Penelitian ini bertujuan untuk menganalisis pengaruh sosio budaya gizi terhadap pemberian ASI eksklusif di wilayah kerja Puskesmas Bangkalan, Madura.

Metode: Penelitian ini menggunakan rancangan cross sectional dengan sampel ibu yang memiliki bayi usia 6-12 bulan. Besar sampel dari penelitian ini yaitu 87 responden. Pengambilan sampel dilakukan dengan stratified random sampling. Pengumpulan data melalui wawancara menggunakan kuesioner dan hasil penelitian dianalisis menggunakan uji regresi logistik.

Hasil: Hasil penelitian menunjukkan bahwa terdapat pengaruh antara sosio budaya gizi pada bayi $(P=0,000)$ terhadap pemberian ASI eksklusif di wilayah kerja Puskesmas Bangkalan. Ibu yang terdapat sosio budaya gizi pada bayi lebih banyak tidak memberikan ASI eksklusif selama 6 bulan

Kesimpulan: Dari hasil penelitian dapat disimpulkan bahwa sosio budaya gizi pada bayi berupa pemberian makanan prelakteal dan MP-ASI dini dapat mempengaruhi pemberian ASI eksklusif pada bayi selama 6 bulan. Diharapkan agar tenaga kesehatan mengedukasi ibu dan suami tentang bahaya memberian madu dan MP-ASI dini kepada bayi serta memotivasi suami agar memberikan dukungan kepada ibu untuk menyusui eksklusif. Meningkatkan peran kader dalam menggerakkan masyarakat agar mau datang dalam penyuluhan tentang ASI eksklusif bersama suami.
\end{abstract}

Kata kunci: ASI eksklusif, sosio budaya gizi, etnik Madura

\section{ABSTRACT}

Background: Breast milk is the best nutrition for children's health and intelligence. Exclusive breastfeeding can prevent death and infectious diseases in infants. The socio-cultural factor is one of the strong driving factors towards mother's behavior in giving exclusive breastfeeding, especially to people who have strong adherence to the traditions of their ancestors such as the Maduranese.

Objectives: The purpose of this study was to analyze the influence of socio-cultural nutrition on exclusive breastfeeding in the Bangkalan Health Center, Madura

Methods: This study was using a cross sectional research design with a sample of mothers who have babies aged 6-12 months. The sample size of this study was 87 respondents. Sampling is done by stratified random sampling. Data collection through interviews using questionnaires and research results were analyzed using logistic regression tests.

Results: There was an influence between socio- culture of nutrition in infants $(P=0,000)$ on exclusive breastfeedingi the Bangkalan public health center. Mothers who have socio-culture of nutrition in infants more do not provide exclusive breastfeeding for 6 months.

Conclusions: In conclusion, socio-culture of nutrition in infants in the form of prelacteal feeding and early MP-ASI can influence exclusive breastfeeding for infants for 6 months. It is hoped that health workers will educate mothers and husbands about the dangers of giving honey and MP-ASI early to babies and motivate husbands to provide support to mothers for exclusive breastfeeding. Increasing the role of cadres in moving the community to want to come in counseling about exclusive breastfeeding with her husband.

Keywords: exclusive breastfeeding, socio culture of nutrition, Maduranese

\author{
*Koresponden: \\ Anis Zaiti Mubarokah \\ Email: aniszaitimubarokah@gmail.com \\ Prodi S1-Kesehatan Masyarakat, Fakultas Kesehatan Masyarakat Universitas Airlangga, Kampus C Mulyorejo, Surabaya, Jawa \\ Timur, Indonesia
}




\section{PENDAHULUAN}

Air Susu Ibu (ASI) merupakan nutrisi pertama yang sangat penting dalam pertumbuhan dan perkembangan bayi. Pemberian ASI kepada bayi diberikan selama enam bulan setelah kelahiran tanpa memberi makanan tambahan apapun kecuali oralit, tetes, dan sirup (vitamin, mineral, dan obat-batan) atau disebut dengan ASI eksklusif ${ }^{1}$. Pemberian ASI eksklusif dapat mencegah terjadinya kematian pada balita, mencegah penyakit infeksi, menurunkan risiko obesitas, stunting, wasting, dan kurang berat badan 23

Berdasarkan data dari WHO tahun 2018, bayi usia 0-6 bulan yang mendapatkan ASI eksklusif sebesar $41 \%$. Angka tersebut masih rendah jika dibandingkan dengan Global Nutritions Targets 2025 yaitu meningkatkan pemberian ASI eksklusif minimal 50\% dan target pada tahun 2030 sebesar $70 \%{ }^{4}$. Secara Nasional, cakupan ASI eksklusif pada bayi usia 0-5 bulan sebesar 37,3\% ${ }^{5}$. Cakupan pemberian ASI eksklusif di Kabupaten Bangkalan masih rendah jika dibandingkan dengan Kota/Kabupaten lain di Jawa Timur. Berdasarkan Data Riskesdas Provinsi Jawa Timur cakupan pemberian ASI eksklusif di Kabupaten Bangkalan yaitu 29,1\% ${ }^{6}$

Terdapat berbagai faktor yang mempengaruhi sikap ibu dalam memberikan ASI eksklusif, baik faktor langsung maupun faktor tidak langsung. Budaya merupakan salah satu faktor tidak langsung yang mempengaruhi pemberian ASI eksklusif, baik budaya pada ibu saat menyusui maupun budaya pada bayi. Penelitian yang dilakukan di kelurahan Sidotopo, Semampir, Surabaya menunjukkan bahwa kepercayaan dan tradisi dalam keluarga berhubungan dengan pemberian ASI eksklusif. Budaya yang ada di masyarakat akan mempengaruhi seseorang berperilaku seperti yang diyakininya. Sebagian individu yang meyakini bahwa pemberian madu dan air manis dapat membuat bayi menjadi kuat akan melakukan hal tersebut pada bayinya?

Madura merupakan salah satu suku yang ada di Jawa Timur yang memiliki keragaman budaya yang melekat erat dalam tatanan sosial masyarakatnya. Penelitian sebelumnya yang dilakukan di desa Ujung Piring Kecamatan Bangkalan menunjukkan bahwa terdapat sosio budaya gizi pada bayi seperti pemberian makanan prelakteal berupa madu dan kelapa muda serta pemberian MP-ASI dini sebelum bayi berumur 6 bulan ${ }^{8}$. Pemberian makanan prelakteal kepada bayi berdampak negatif terhadap kesehatan karena dapat menyebabkan kejadian sakit pada bayi. Pemberian makanan prelakteal menghambat bayi untuk mendapatkan ASI berupa kolostrum yang dapat meningkatkan sistem imun tubuh sebagai pelindung dari berbagai penyakit ${ }^{9}$.

Berdasarkan data Dinas Kesehatan Kabupaten Bangkalan tahun 2018, Puskesmas Bangkalan memiliki cakupan ASI eksklusif yang rendah yaitu $23,4 \%$. Penelitian ini bertujuan untuk menganalisis pengaruh aspek sosio budaya gizi terhadap pemberian ASI eksklusif di wilayah kerja Puskesmas Bangkalan.

\section{METODE}

Penelitian ini merupakan penelitian observasional analitik dengan desain penelitian cross sectional yang dilaksanakan di wilayah kerja Puskesmas Bangkalan, Kecamatan Bangkalan, Kabupaten Bangkalan. Penelitian ini telah mendapatkan persetujuan lolos kaji etik oleh KEPK Fakultas Keperawatan Universitas Airlangga dengan nomor etik 1489-KEPK.

Sampel penelitian adalah 87 bayi yang berusia 6 12 bulan yang memenuhi kriteria bayi tidak memiliki riwayat penyakit serius (seperti HIV, TBC). Pemilihan sampel dalam penelitian ini menggunakan stratified random sampling, yaitu membagi populasi di wilayah kerja Puskesmas Bangkalan yang terdiri dari 13 desa menjadi 3 kelompok (strata) antara lain kelompok yang memiliki cakupan ASI eksklusif rendah, sedang, dan tinggi. Pengambilan sampel pada populasi terpilih dilakukan secara random (acak).

Pengumpulan data tentang karakteristik ibu (meliputi usia, tingkat pendidikan, tingkat pendapatan keluarga, status pekerjaan, paritas), dan sosio budaya gizi pada bayi dilakukan dengan wawancara menggunakan kuesioner kepada ibu bayi. Pengaruh terhadap variabel penelitian dianalisis menggunakan uji regresi logistik.

\section{HASIL DAN PEMBAHASAN}

\section{Pemberian ASI Eksklusif}

Hasil penelitian yang dilakukan pada 87 responden di wilayah Kerja Puskesmas Bangkalan menunjukkan bahwa sebagian besar bayi tidak mendapatkan ASI eksklusif, yaitu sebesar $77 \%$. Distribusi pemberian ASI eksklusif di wilayah Kerja Puskesmas Bangkalan dapat dilihat dalam Tabel 1.

Tabel 1. Ditribusi Pemberian ASI di Wilayah Kerja Puskesmas Bangkalan Tahun 2019

\begin{tabular}{lcc}
\hline \multicolumn{1}{c}{ Pemberian ASI } & $\mathbf{n}$ & $\mathbf{\%}$ \\
\hline ASI Eksklusif & 20 & 23,0 \\
Tidak ASI Eksklusif & 67 & 77,0 \\
\hline Total & 87 & 100 \\
\hline
\end{tabular}

\section{Karakteristik Ibu}

Karakteristik responden yang meliputi usia, tingkat pendidikan, tingkat pendapatan keluarga, status pekerjaan, dan paritas berperan dalam pola pengasuhan bayi. Karakteristik responden dalam penelitian ini tersaji dalam Tabel 2.

Tabel 2. Distribusi Karakteristi Responden di Wilayah Kerja Puskesmas Bangkalan Tahun 2019

\begin{tabular}{lcc}
\hline Karakteristik Responden & Jumlah & $\%$ \\
\hline Usia Ibu & & \\
$\quad<20$ tahun & 2 & 2,3 \\
$20-35$ tahun & 66 & 75,9 \\
$\quad>35$ tahun & 19 & 21,8 \\
$\begin{array}{l}\text { Pendidikan Ibu } \\
\text { Lulus SD }\end{array}$ & & \\
$\quad$ Lulus SMP & 16 & 18,4 \\
$\quad$ Lulus SMA & 17 & 19,5 \\
$\quad$ Lulus Diploma/Sarjana & 26 & 29,9 \\
Status Pekerjaan & 28 & 32,2 \\
$\quad$ Bekerja & & \\
$\quad$ Tidak Bekerja & 22 & 25,3 \\
$\quad$ Paritas & 65 & 74,7 \\
$\quad$ Primipara & & \\
$\quad$ Multipara & 17 & 19,5 \\
\hline
\end{tabular}


Tabel 2 menunjukkan bahwa sebagian besar usia ibu adalah 20 - 35 tahun (75,9\%). Usia ibu berhubungan dengan pemberian ASI eksklusif. Ibu yang memiliki usia lebih tua memiliki kemungkinan menyusui lebih kecil dibandingkan dengan usia muda ${ }^{10}$. Penelitian di Brazil menunjukkan bahwa tingkat pemberian ASI eksklusif pada ibu usia $>35$ tahun lebih rendah dibandingkan dengan usia 20-35 tahun dan lebih tinggi jika dibandingkan dengan usia $<20$ tahun ${ }^{11}$.

Tingkat pendidikan responden lebih banyak lulus Diploma/Sarjana (32,2\%). Ibu dengan tingkat pendidikan yang tinggi memiliki keberhasilan yang lebih tinggi dalam memberikan ASI eksklusif. Semakin tinggi tingkat pendidikan, semakin tinggi pula kemampuan berfikir seseorang sehingga berpengaruh terhadap keputusan dalam memberikan ASI eksklusif ${ }^{12}$.

Sebagian besar responden tidak bekerja $(74,7 \%)$ sedangkan ibu yang bekerja diantaranya sebagai guru, tenaga kesehatan, pegawai negeri sipil, pedagang, dan nelaya. Ibu yang bekerja memiliki waktu yang lebih sedikit dengan anak sehingga ibu tidak bisa mengawasi perkembangan dan pola asuh anak selama 24 jam termasuk pemberian makanan kepada anak ${ }^{13}$

Sebagian besar responden adalah ibu multipara (80,5\%). Ibu multipara memiliki produksi ASI yang cukup banyak bahkan ASI sudah mulai keluar menjelang persalinan. Pengalaman menyusui sebelumnya dapat menentukan keberhasilan dalam memberikan ASI eksklusif. Hal ini karena ibu yang memiliki pengalaman menyusui lebih mudah mengatasi hambatan selama memberikan ASI ${ }^{14}$.

\section{Sosio Budaya Gizi}

Berdasarkan hasil penelitian, bayi yang mendapatkan ASI eksklusif sebesar $23 \%$. Secara nasional, angka ini belum memenuhi target capaian ASI eksklusif yaitu sebesar $47 \%{ }^{15}$. Hal ini dikarenakan masyarakat pada etnik Madura memiliki sosio budaya gizi pada pada bayi yang masih melekat erat di masyarakat. Budaya akan memberikan pengaruh yang kuat di masyarakat sehingga muncul sikap falistis (yaitu keyakinan yang kuat terhadap budayanya) dan sikap ethnocentris (yaitu sikap menganggap tradisinya adalah yang paling baik). Kedua sikap tersebut apabila ada dalam masyarakat akan mempengaruhi praktik kesehatan karena menganggap budayanya adalah yang paling benar dan sehat ${ }^{16}$.

Berdasarkan Tabel 3, terdapat beberapa sosio budaya gizi pada bayi yang dapat mempengaruhi pemberian ASI eksklusif. Sosio budaya gizi pada bayi yang ada di masyarakat antara lain memberikan makanan prelakteal kepada bayi, yaitu memberikan madu $(37,9 \%)$ dan kelapa muda (ro'mero') setelah lahir $(27,6 \%)$. Pemberian madu pada bayi dilakukan dengan mengolesi bibir bayi menggunakan tangan dengan tujuan untuk mengenalkan rasa makanan kepada bayi. Kelapa muda diberikan kepada bayi dengan alasan kelapa muda mudah dicerna karena teksturnya yang lembut.

Sosio budaya gizi pada bayi berikutnya adalah pemberian MP-ASI dini kepada bayi sebelum usia 6 bulan (48,3\%). MP-ASI berupa pisang pdan bubur (dibuat sendiri dari nasi yang dihaluskan atau bubur instan. Alasan ibu memberikan MP-ASI sejak dini karena dapat mengenalkan makanan padat kepada bayi sehingga bayi tidak kaget ketika harus diberi MP-ASI setelah usia 6 bulan ke atas. Tidak jarang ibu sudah memberi makanan padat kepada bayi ketika usia 2 bulan atau kurang dari 5 bulan.

Hal tersebut dilakukan karena masyarakat meyakini bahwa bayi yang menangis terus menerus setelah disusui masih merasakan lapar sehingga perlu diberi makanan tambahan seperti pisang atau bubur agar bayi dapat tenang dan tertidur. Selain itu, bayi yang diberi pisang dan bubur akan merasa lebih kenyang sehingga ketika ditinggal bekerja bayi tidak rewel. Pemberian makanan tambahan terlalu dini dapat menyebabkan gangguan pada system pencernaan, seperti diare, muntah, dan konstipasi. Hal ini terjadi karena pada usia kurang dari 6 bulan sistem pencernaan bayi belum bisa bekerja dengan sempurna. Faktor lain yang dapat menyebabkan bayi sakit adalah penyajian makanan yang kurang hygiene sehingga penyerapan usus terganggu 17 .

Berdasarkan Tabel 4 diperoleh hasil uji statistik yang menunjukkan bahwa sosio budaya gizi pada bayi berpengaruh terhadap pemberian ASI eksklusif di wilayah kerja Puskesmas Bangkalan $(p=0,000)$. Ibu yang terdapat sosio budaya gizi pada bayi lebih banyak tidak memberikan ASI eksklusif dibandingkan dengan ibu yang tidak terdapat sosio budaya gizi pada bayi, sebesar $96,6 \%$. Beberapa ibu mengatakan jika yang memberikan madu dan kelapa muda kepada bayi adalah orang tua. Madu dan kelapa muda tersebut diberikan setelah bayi pulang dari rumah sakit atau dari bidan desa. Menurut ibu, pemberian madu tidak akan mempengaruhi kesehatan bayi karena hanya diberikan sekali dan sedikit.

Tabel 3. Distribusi Sosio Budaya Gizi di Wilayah Kerja Puskesmas Bangkalan Tahun 2019

\begin{tabular}{lcc}
\multicolumn{1}{c}{ Sosio Budaya Gizi pada Bayi } & Jumlah & $\%$ \\
\hline Setelah lahir, bayi diberikan madu & 33 & 37,9 \\
Bayi diberikan kelapa muda setelah atau beberapa hari setelah lahir & 24 & 27,6 \\
Memberikan MP-ASI dini sebelum bayi berusia 6 bulan & 42 & 48,3 \\
\hline
\end{tabular}

Tabel 4. Pengaruh Sosio Budaya Gizi terhadap Pemberian ASI Eksklusif di wilayah Kerja Puskesmas Bangkalan Tahun 2019

\begin{tabular}{lccccccc}
\hline \multirow{2}{*}{ Sosio Budaya Gizi pada Bayi } & \multicolumn{2}{c}{ ASI Eksklusif } & \multicolumn{2}{c}{ Tidak ASI Eksklusif } & \multicolumn{2}{c}{ Total } & \multirow{2}{*}{$\boldsymbol{P}$ value } \\
\cline { 2 - 8 } & $\mathbf{n}$ & $\boldsymbol{\%}$ & $\mathbf{n}$ & $\boldsymbol{\%}$ & $\mathbf{n}$ & $\mathbf{\%}$ & 0,000 \\
\hline Ada & 2 & 3,4 & 56 & 96,6 & 58 & 100 & 0 \\
Tidak Ada & 18 & 62,1 & 11 & 37,9 & 29 & 100 & \\
\hline
\end{tabular}


Penelitian ini sejalan dengan penelitian yang dilakukan di wilayah kerja Panarung, Kota Palangkaraya yang menyebutkan bahwa kegagalan pemberian ASI eksklusif disebabkan karena adanya budaya pemberian makanan prelakteal kepada bayi dari orang tua dan lingkungan sekitar, seperti pemberian air kopi, air gula merah, santan kental, atau madu hutan ${ }^{18}$. Penelitian pada etnis Korogoncho dan Viwandani, Kenya juga menunjukkan bahwa kegagalan pemberian ASI eksklusif disebabkan karena pengaruh budaya seperti pemberian air yang dicampur dengan garam dan gula pada bayi setelah hari kedua dan ketiga kelahiran ${ }^{19}$.

Pemberian makanan prelakteal maupun makanan tambahan sebelum bayi berusia 6 bulan keatas berdampak buruk pada kesehatan bayi. Pemberian makanan prelakteal dapat menyebabkan kejadian sakit pada bayi, seperti Infeksi Saluran Pernafasa Akut (ISPA) dan demam yang disebabkan karena sistem imunitas yang menurun. Banyak dan lamanya pemberian makanan prelakteal berpengaruh terhadap sakit yang dialami oleh bayi ${ }^{9}$.

Selain orang tua, dukungan suami juga berperan penting dalam keberhasilan pemberian ASI eksklusif. Beberapa penelitian menunjukkan bahwa ibu yang mendapatkan dukungan suami selama menyusui lebih banyak memberikan ASI eksklusif dibandingkan yang tidak ada dukungan suami. Dukungan suami kepada istri selama menyusui dapat berupa dukungan emosional, informasional, perhatian lebih kepada istri, memperhatikan nutrisi istri selama menyusui, serta membantu merawat bayi dan menyelesaikan pekerjaan rumah tangga 202122.

Berdasarkan penelitian, kurangnya dukungan suami menyebabkan motivasi dan keinginan ibu untuk menyusui eksklusif tidak sekuat ibu yang mendapatkan dukungan penuh dari suaminya. Ibu yang mendapatkan dukungan dari suami lebih tegas menolak budaya dalam keluarga seperti pemberian madu setelah bayi lahir dengan alasan suami menginginkan bayinya hanya diberi ASI saja selama 6 bulan penuh. Kurangnya dukungan suami antara lain seperti ketidakhadiran suami selama melahirkan dan menyusui karena bekerja di luar kota, tidak ada perhatian khusus kepada istri selama menyusui, dan suami cenderung menyerahkan urusan merawat bayi kepada istri saja.

Pemberian ASI eksklusif kepada bayi selama 6 bulan merupakan hak bayi yang harus dipenuhi oleh ibu sebagaimana telah diatur dalam Pasal 2 Peraturan Pemerintah Republik Indonesia Nomor 33 Tahun 2012 tentang Pemberian Air Susu Ibu Eksklusif ${ }^{23}$. Program yang dijalankan Puskesmas Bangkalan dalam meningkatkan pemberian ASI eksklusif selama ini adalah penyuluhan kepada ibu hamil dan menyusui saja. Peran kader sebagai kepanjangan tangan dari Puskesmas juga sangat kurang, padahal kader memiliki peran penting dalam keberhasilan pemberian ASI eksklusif karena kader tinggal dan bergaul bersama masyarakat setempat.

\section{KESIMPULAN}

Sosio budaya gizi pada bayi seperti pemberian madu dan kelapa muda serta pemberian MP-ASI berupa pisang dan bubur sebelum bayi berusia 6 bulan menghambat ibu dalam memberikan ASI eksklusif. Kurangnya dukungan suami merupakan salah satu yang menyebabkan motivasi ibu dalam memberikan ASI eksklusif rendah sehingga terpengaruh dengan pola asuh orang tua dan lingkungan sekitar. Diharapkan petugas kesehatan dapat memberikan edukasi kepada ibu dan suami tentang dampak negatif pemberian MP-ASI dini pada bayi. Petugas kesehatan juga dapat memberikan motivasi kepada suami agar mendukung ibu dalam pemberian ASI eksklusif seperti membantu istri merawat bayi, ikut bangun malam menemani istri menyusui, dan membantu istri dalam menyelesaikan pekerjaan rumah. Kedua, mengaktifkan peran kader sebagai kepanjangan tangan petugas kesehatan untuk menggerakkan ibu agar datang bersama suami ketika terdapat penyuluhan tentang ASI eksklusif.

\section{ACKNOWLEDGEMENT}

Ucapan terima kasih diberikan kepada kepala Puskesmas Bangkalan, Madura karena telah mengizinkan peneliti untuk melakukan penelitian dan pengambilan data di wilayah kerja Puskesmas Bangkalan. Selain itu, peneliti juga mengucapkan terima kasih kepada seluruh petugas gizi dan bidan Puskesmas Bangkalan yang telah membantu dalam mengumpulkan data serta masyarakat di wilayah kerja Puskesmas yang telah bersedia menjadi responden.

\section{CONFLICT OF INTEREST AND FUNDING DISCLOSURE}

Semua penulis tidak memiliki konflik kepentingan dalam artikel penelitian ini. Penelitian ini tidak didanai oleh sponsor. Sumber dana dalam penelitian ini dari dana pribadi.

\section{REFERENS}

1. WHO. Up to What Age Can a Baby Stay Well Nourished by Just Being Breastfed? https://www.who.int/features/qa/21/en/ (2015).

2. Kumar, A. \& Singh, V. K. A Study of Exclusive Breastfeeding and its impact on Nutritional Status of Child in EAG States. J. Stat. Appl. Probab. 445, 435-445 (2015).

3. Victora, C. G. et al. Breastfeeding in the 21st Century: Epidemiology, Mechanisms, and Lifelong Effect. Lancet 387, 475-490 (2016).

4. WHO. Global Breastfeeding Scorecard, 2018 Enabling Women to Breastfeed Through Better Policies and Call to Action Priorities. (WHO, 2018).

5. Kemenkes RI. Hasil Utama Riskesdas 2018. http://www.depkes.go.id/resources/download/i nfo-terkini/hasil-riskesdas-2018.pdf http://www.depkes.go.id/resources/download/ info-terkini/hasil-riskesdas-2018.pdf (2018).

6. Kemenkes RI. Hasil Utama Riskesdas 2018 Provinsi Jawa Timur. http://www.dinkes.kedirikab.go.id/konten/uu/2 2033-hasil-riskesdas-jatim-2018.pdf 1-82 (2018). 
7. Setyaningsih, F. T. E. \& Farapti, F. Hubungan Kepercayaan dan Tradisi Keluargapada Ibu Menyusui dengan Pemberian ASI Eksklusif di Kelurahan Sidotopo, Semampir, Jawa Timur. J. Biometrika dan Kependud. 7, 160-167 (2018).

8. Illahi, R. K. \& Muniroh, L. Gambaran Sosio Budaya Gizi Etnik Madura dan Kejadian Stunting Balita Usia 24-59 Bulan di Bangkalan. Media Gizi Indones. 11, 135-143 (2015).

9. Harahap, D., Indriati, G. \& Wofers, R. Hubungan Pemberian Makanan Prelakteal Terhadap Kejadian Sakit Pada Neonatus. JOM FKp 6, 72-80 (2019).

10. Colombo, L. et al. Breastfeeding Determinants in Healthy Term Newborns. Nutrients 10, 1-10 (2018).

11. Silva, V. A. A. L. et al. Maternal Breastfeeding: Indicators and Factors Associated with Exclusive Breastfeeding in a Subnormal Urban Cluster Assisted by the Family Health Strategy. J. Pediatr. (Rio. J). 1, 1-8 (2018).

12. Widiyanto, S., Aviyanti, D. \& A, M. T. Hubungan Pendidikan dan Pengetahuan Ibu tentang ASI Eksklusif dengan Sikap terhadap Pemberian ASI Eksklusif Subur. J. Kedokt. Muhammadiyah 1, 25-29 (2012).

13. Salimar, Hastuti, D. \& Melly, L. Hubungan Beban Kerja, Pengetahuan Ibu, dan Pola Asuh Psikososial Dengan Perkembangan Kognitif Anak Usia 2-5 Tahun pada Keluarga Miskin. PGM 34, 39-49 (2011).

14. Oliveira, M. M. de. Gestational, Perinatal, and Postnatal Factors that Interfere with Practice of Exclusive Breastfeeding by Six Months After Birth. Int. Breastfeed. J. 12, 1-9 (2017).

15. Kemenkes RI. Rencana Strategi Kementrian
Kesehatan

2015-2019.

http://www.depkes.go.id/resources/download/i nfo-publik/Renstra-2015.pdf (2015).

16. Notoatmodjo, S. Promosi Kesehatan Teori dan Aplikasi. (PT Rineka Cipta, 2005).

17. Winarsih, B. D. \& Zumrotun, Z. Hubungan Pemberian Makanan Tambahan Usia Dini Dengan Kejadian Gangguan Sistem Pencernaan Pada Bayi Usia 0-6 Bulan Di Puskesmas Bangsri I Kecamatan Bangsri Kabupaten Jepara. J. Keperawatan dan Kesehat. Masy. Cendekia Utama 1, (2012).

18. Hervilia, D., Dhini \& Munifa. Pandangan Sosial Budaya terhadap ASI Eksklusif di Wilayah Panarung Palangkaraya. Indones. J. Hum. Nutr. 3, 63-70 (2016).

19. Wanjohi, M. et al. Sociocultural Factors Influencing Breastfeeding Practices in Two Slums in Nairobi, Kenya. Int. Breastfeed. J. 12, 1-8 (2017).

20. Kusumayanti, N. \& Nindya, T. S. Hubungan Dukungan Suami dengan Pemberian ASI Eksklusif di Daerah Perdesaan. Media Gizi Indones. 12, 98-106 (2016).

21. Wahyuningsih, D. \& Machmudah. Dukungan Suami dalam Pemberian Asi Eksklusif. $J$. Keperawatan Matern. 1, 93-101 (2013).

22. Mufdlilah, M., Zulfa, S. Z. \& Johan, R. B. Buku Panduan Ayah ASI. (Nuha Medika, 2019).

23. Peraturan Pemerintah Republik Indonesia Nomor 33 Tahun 2012 Tentang Pemberian Air Susu Ibu Eksklusif. http://www.hukor.depkes.go.id/uploads/produ k_hukum/PP\%20No.\%2033\%20ttg\%20Pemberia n\%20ASI\%20Eksklusif.pdf. 